\title{
Review \\ The Role of Immunotherapy in the Treatment of Advanced Cervical Cancer: Current Status and Future Perspectives
}

\author{
Robert J. Walsh ${ }^{1}$ and David S. P. Tan ${ }^{1,2, *(D)}$ \\ 1 National University Cancer Institute, Singapore 119074, Singapore; robert_walsh@nuhs.edu.sg \\ 2 Cancer Science Institute, National University of Singapore, Singapore 117599, Singapore \\ * Correspondence: david_sp_tan@nuhs.edu.sg
}

Citation: Walsh, R.J.; Tan, D.S.P. The Role of Immunotherapy in the Treatment of Advanced Cervical Cancer: Current Status and Future Perspectives. J. Clin. Med. 2021, 10, 4523. https://doi.org/10.3390/ jcm10194523

Academic Editors: Gemma G. Kenter and Ekaterina S. Jordanova

Received: 30 June 2021

Accepted: 27 September 2021

Published: 29 September 2021

Publisher's Note: MDPI stays neutral with regard to jurisdictional claims in published maps and institutional affiliations.

Copyright: (C) 2021 by the authors. Licensee MDPI, Basel, Switzerland. This article is an open access article distributed under the terms and conditions of the Creative Commons Attribution (CC BY) license (https:/ / creativecommons.org/licenses/by/ $4.0 /)$.

\begin{abstract}
Cervical cancer remains one of the most common cancers in women around the world however therapeutic options in the advanced and recurrent setting are limited. Immune checkpoint inhibitors (ICI) have been considered an attractive option given the viral etiology of cervical cancer although the majority of patients do not benefit from their use. This review summarises current knowledge and use of immune checkpoint blockade in cervical cancer as well as discussing the challenges faced in their clinical application, namely, the role of biomarker-driven ICI use, potential mechanisms of resistance, strategies to overcome such resistance and additional immunotherapy options beyond ICI.
\end{abstract}

Keywords: cervical cancer; immunotherapy; immune checkpoint inhibitor

\section{Introduction}

Cervical cancer remains the 4th most commonly occurring cancer in women globally, despite ongoing preventive efforts with progressive human papilloma virus (HPV) vaccination programs in developed countries [1,2]. Treatment of a majority of early stage cervical cancer involves definitive chemoradiotherapy, however relapse rates at five years remain above $20 \%$ after this curative intent therapy [3].

In the setting of metastatic and recurrent cervical cancer, treatment options beyond that of first line chemotherapy combined with bevacizumab are limited, with second line single agent chemotherapy offering response rates in the region of $15-20 \%$ [4-6] and median survival times remaining under two years [7]. It had been hoped that the role of persistent HPV infection in cervical cancer pathogenesis [2] would leave this disease vulnerable to the effects of immune checkpoint inhibitors (ICI) however results, primarily with monotherapy ICI, have been modest to date.

Here, we discuss the current status of immunotherapy in cervical cancer including approved indications, published ICI monotherapy and combination strategies as well as immune modulation therapeutics beyond ICI. Challenges including biomarker identification and resistance mechanisms will be discussed.

\section{Immune Response to Cancer and Immune Checkpoint Inhibition: Rationale for Immunotherapy in Cervical Cancer}

The 'cancer immunity cycle' describes the events required for the development of an immune response to cancers [8]. Cell death leads to the release of tumour associated antigens which are phagocytosed, processed and presented via major histocompatibility complex (MHC) of antigen presenting cells (APC). Naive T-cells are activated by these non-self antigens and transit and infiltrate the tumour, with $\mathrm{CD} 8^{+} \mathrm{T}$-cells and natural killer cells subsequently enacting cytotoxic cell death.

Immune checkpoints function as negative regulators of this cycle, with programmed death 1 (PD-1) and cytotoxic T lymphocyte antigen (CTLA-4) being the most studied. 
Tumours exploit these inhibitory pathways to evade host immune surveillance [9]. Interruption of these pathways with antibodies against targets including PD-1, its ligand programmed death ligand 1 (PD-L1) and CTLA-4 aim to facilitate a host immune response against the tumour, acting as immune checkpoint inhibitors (ICI). Use of ICI has dramatically altered the treatment landscape in many solid organ malignancies including lung, renal cell carcinoma, melanoma and colorectal cancer [10-13].

The role of HPV in the pathogenesis of cervical cancer gives insights into potential therapeutic benefit of ICI in this tumour. The majority of cases of cervical cancer are associated with high-risk HPV (16 or 18) which encode E5, E6 and E7 proteins that drive malignant transformation. These proteins are implicated in the PD1/PDL1 pathway leading to increased PD-L1 expression [14] potentially propagating immune evasion.

\section{ICI Monotherapy and Combination in Cervical Cancer}

Several studies have explored the role of ICI monotherapy and combination in advanced cervical cancer. These include the anti-PD1 (pembrolizumab, nivolumab and cemiplimab), anti-PDL1 (durvalumab) and anti-CTLA4 (Ipilimumab, tremelimumab) monoclonal antibodies. A summary of ICI monotherapy trials is shown in Table 1.

Table 1. Reported trials of ICI single agent therapy in advanced cervical cancer.

\begin{tabular}{|c|c|c|c|c|c|c|}
\hline Trial & $\begin{array}{c}\text { No. of } \\
\text { Subjects }\end{array}$ & $\begin{array}{l}\text { Included } \\
\text { Subjects }\end{array}$ & Intervention & ORR (\%) & $\begin{array}{c}\text { mDOR } \\
\text { (Months) }\end{array}$ & Survival (Months) \\
\hline $\begin{array}{l}\text { EMPOWER- } \\
\text { CERVICAL 1/ } \\
\text { GOG-3016/ } \\
\text { ENGOT-CX9 [15] }\end{array}$ & 608 & $\begin{array}{l}\text { PDL1 unselected } \\
\geq 1 \text { prior line of } \\
\text { therapy }\end{array}$ & $\begin{array}{c}\text { Cemiplimab } 350 \mathrm{mg} \\
3 \text { weekly } \\
\text { vs. } \\
\text { Investigator choice } \\
\text { chemotherapy }\end{array}$ & 16.4 vs. 6.3 & 16.4 vs. 6.9 & $\begin{array}{c}\text { mPFS: } 2.8 \text { vs. } 2.9 \\
(\mathrm{HR}=0.75[0.63-0.89]) \\
\text { mOS: } 12.0 \text { vs. } 8.5 \\
(\mathrm{HR}=0.69[0.56-0.84])\end{array}$ \\
\hline $\begin{array}{c}\text { KEYNOTE-028 } \\
{[16]}\end{array}$ & 24 & $\begin{array}{l}\text { PD-L1 } \geq 1 \% \\
\text { (modified } \\
\text { proportion score) } \\
\text { PD on prior } \\
\text { therapy }\end{array}$ & $\begin{array}{c}\text { Pembrolizumab } \\
10 \mathrm{mg} / \mathrm{kg}, 2 \text { weekly }\end{array}$ & 17 & $5.4 \mathrm{~m}$ & $\begin{array}{l}\text { mPFS } 2 \\
\text { mOS } 11\end{array}$ \\
\hline $\begin{array}{c}\text { KEYNOTE-158 } \\
\text { [17] }\end{array}$ & 98 & $\begin{array}{l}\text { PDL1 unselected } \\
\text { PD on prior } \\
\text { therapy }\end{array}$ & $\begin{array}{l}\text { Pembrolizumab } \\
200 \text { mg } 3 \text { weekly }\end{array}$ & $\begin{array}{c}12.2(\text { PDL1 } \\
\text { unselected }) \\
14.6(\text { PDL1 CPS } \geq 1)\end{array}$ & NR & $\begin{array}{c}\text { mPFS } 2.1 \\
\text { mOS } 9.4 \text { (ITT) }\end{array}$ \\
\hline $\begin{array}{l}\text { CHECKMATE- } \\
358 \text { [18] cervical } \\
\text { cohort }\end{array}$ & 19 & $\begin{array}{c}\leq 2 \text { prior lines of } \\
\text { therapy } \\
\text { Excluded HPV } \\
\text { negative }\end{array}$ & $\begin{array}{l}\text { Nivolumab } 240 \mathrm{mg} \\
2 \text { weekly }\end{array}$ & 26.3 & NR & $\begin{array}{l}\text { mPFS } 5.1 \\
\text { mOS } 21.9\end{array}$ \\
\hline NRG-GY002 [19] & 25 & $\begin{array}{l}\text { PDL1 unselected } \\
\text { PD on prior } \\
\text { therapy }\end{array}$ & $\begin{array}{l}\text { Nivolumab } 3 \mathrm{mg} / \mathrm{kg} \\
2 \text { weekly }\end{array}$ & 4 & 3.8 & $\begin{array}{l}\text { mPFS } 3.5 \\
\text { mOS } 14.5\end{array}$ \\
\hline $\begin{array}{l}\text { Lheureux et al. } \\
\text { [20] }\end{array}$ & 42 & PDL1 unselected & $\begin{array}{c}\text { Ipilimumab } 10 \mathrm{mg} / \mathrm{kg} \\
3 \text { weekly (4 cycles) } \rightarrow \\
12 \text { weekly maintenance } \\
\text { (to } 1 \text { year) }\end{array}$ & 3 & - & $\begin{array}{c}\text { mPFS } 2.5 \\
\text { mOS } 8.5\end{array}$ \\
\hline
\end{tabular}

mDOR, median duration of response; ORR, objective response rate; HR, hazard ratio; mOS, median overall survival; mPFS, median progression free survival; PD, progressive disease; $\mathrm{m}$, months; NR, not reached.

\subsection{Pembrolizumab}

KEYNOTE-028, a single arm study of Pembrolizumab in recurrent squamous cell carcinoma (SCC) cervix showed an overall response rate (ORR) of 17\% in 24 PDL1 positive patients [16]. KEYNOTE-158, a basket study including a cohort of patients with advanced cervical cancer, helped to identify PDL1 as a biomarker for response. Patients ( $\mathrm{n}=98)$ were recruited regardless of PDL1 status and received 3 weekly pembrolizumab $200 \mathrm{mg}$ for up to 2 years, with $94 \%$ being squamous histology. ORR was $12.2 \%$ in the entire study population however responses were only seen in the PDL1 positive subgroup (83.7\% of study population), with PDL1 positivity determined by a combined positive score (CPS) of $\geq 1$ based on $22 \mathrm{C} 3$ assay. ORR was $14.6 \%$ in the PDL1 positive group and median duration 
of response was not reached [17]. As a result, pembrolizumab gained US Food and Drug Administration (FDA) approval in pre-treated PDL1 positive (CPS $\geq 1$ ) cervical cancer in 2018 [21].

\subsection{Nivolumab}

The anti-PD1 antibody nivolumab gave an encouraging ORR of $26.3 \%$ in preliminary analysis of Checkmate-358, a study of patients with advanced cervical cancer with $\leq 2$ prior lines of therapy [18]. Patients with known HPV negative tumours were excluded although testing was not mandated for enrolment. PD-L1 status was assessed with 28-8 pharmDx assay with responses seen in both PD-L1 negative and positive tumours.

A smaller study of nivolumab involving 26 patients with pre-treated advanced cervical SCC reported a lower ORR of $4 \%$, with a further 4 patients having an unconfirmed response. The median overall survival (OS) of 14.3 months was however promising [19] and may highlight a difficulty in assessment of treatment response in the setting of immunotherapy use.

\subsection{Other Anti-PD-1 Agents}

The EMPOWER-Cervical-1 phase III study compared cemiplimab versus physicians choice chemotherapy (pemetrexed, irinotecan, topotecan, gemcitabine, vinorelbine) in patients with advanced cervical cancer after $\geq 1$ lines of treatment who have progressed within 6 months of platinum therapy, regardless of PD-L1 status. The primary endpoint of OS showed significant benefit for cemiplimab over chemotherapy with median OS of 12 versus 8.5 months, respectively, with benefit seen in SCC and non-SCC histology groups. Response rates were encouraging at $16.4 \%$ with estimated median DOR of 16.4 months.

AGEN2034, an anti-PD1 monoclonal antibody, showed clinical activity in phase I studies of patients with breast, ovarian and cervical cancer, with an ongoing phase II study in recurrent advanced cancer [22].

\subsection{Anti-CTLA-4 Therapy}

Monotherapy with the anti-CTLA4 agent ipilimumab showed only modest efficacy in a phase II study of both SCC and adenocarcinoma of cervix with prior exposure to platinum chemotherapy. Of 34 evaluable patients 1 showed partial response [20].

\subsection{Anti-PD-1/PD-L1 and Anti CTLA-4 Combinations}

Single agent ICI has provided encouraging but nonetheless modest results, with high rates of primary resistance observed in the studies discussed above. One possible mechanism underpinning such resistance is the concept of immune escape in both the priming and effector stages of the immune response. Priming of T-cells within lymph nodes requires not only antigen presentation but a costimulatory signal through the interaction of B7 family molecules and the T-cell expressed CD-28. CTLA-4 binds to B7 with high affinity thus inhibiting the costimulatory signal. At the tumour level immune activation leads to interferon release and subsequently an increase in PDL1 expression, thereby inhibiting T-cell response. Simultaneous blockade of both PD1/PDL1 and CTLA-4 checkpoints thus seems a rational way to attempt to increase immune response and treatment efficacy [23]. Such a combination (anti-PD1/PDL1 and anti-CTLA4) has been shown to be effective in several tumour groups leading to approvals in the first line advanced setting in mesothelioma [24], renal cell carcinoma [25], melanoma and non-small cell lung cancer (NSCLC) [25]. This approach has been explored in advanced cervical cancer.

Checkmate-358 reported outcomes for nivolumab and ipilimumab administered at 2 different dose combinations: Nivolumab $3 \mathrm{mg} / \mathrm{kg} 2$ weekly with ipilimumab $1 \mathrm{mg} / \mathrm{kg}$ 6 weekly (combination A) and nivolumab $1 \mathrm{mg} / \mathrm{kg}$ with ipilimumab $3 \mathrm{mg} / \mathrm{kg} 3$ weekly for 4 doses followed by nivolumab maintenance 2 weekly (combination $B$ ). The response rate was higher with combination B versus A with ORR of 41.3 and $26.7 \%$, respectively. Responses were also seen in patients with PD-L1 negative tumours $(2 / 14,14.3 \%$ combi- 
nation A; 4/11 36.4\%, combination B). Survival at 12 months in patients without prior treatment was encouraging in both arms with rates of 83.5 and $78 \%$ for combination $A$ and $B$, respectively [26].

Results of two trials of balstilimab (anti-PD1) alone and in combination with zalifrelimab (anti-CTLA-4) in patients with advanced cervical cancer (SCC or adenocarcinoma) progressing after platinum therapy, were presented at ESMO 2020 with higher response rates seen in the trial of combination therapy [27]. ORR in the single arm study of balstilimab alone was $14 \%$ with $10 \%$ of PDL1 negative tumours showing treatment response. ORR of $22 \%$ was seen in the combination trial of balstilimab and zalifrelimab with responses again seen in both PDL1 positive (ORR 27\%) and PDL1 negative tumours (ORR $11 \%$ ). Of note, responses were seen in both SCC and adenocarcinoma with both single agent balstilimab and combination therapy.

The anti-PDL1 antibody durvalumab in combination with tremelimumab had limited activity in a phase I study with no responses seen in cervical cancer patients although stable disease more than 24 weeks was seen in 15.4\% [28]. Other combinations under investigations include AGEN1884 (anti-CTLA-4) and AGEN2034 (anti-PD-1), with safety data reported from a phase I/I trial including patients with refractory solid organ malignancies (expansion in patients with cervical cancer) [29].

\subsection{Role for ICI in Small Cell Neuroendocrine Carcinoma of the Cervix}

Neuroendocrine carcinoma of the cervix (NECC) is an uncommon histology reported in $1.4 \%$ cervical cancers [30]. The most common variant is small cell NECC which runs an aggressive course and has poor prognosis. The optimal treatment strategy is unclear as is the efficacy of ICI with large studies currently lacking, however case reports point to potential role, with nivolumab resulting in radiologic complete response in one patient with metastatic PDL1 negative small cell NECC [31].

Analysis showing a high rate of HPV positivity suggests a viral role in the aetiology of NECC as seen in cervical SCC [32]. This viral pathogenic factor provides reasoning for further investigation of the use of ICI therapy in this histological subgroup. Furthermore, in first line treatment of the morphologically similar small cell lung cancer (SCLC) anti-PDL1 therapy has been shown to improve OS when used in combination with platinum-based chemotherapy in two phase III studies $[33,34]$. However, in pre-treated SCLC single agent ICI shows only modest results contributing to the voluntary withdrawal of approval for nivolumab for use in treatment refractory SCLC [35].

\section{Challenges of ICI Therapy in Cervical Carcinoma}

Results of studies discussed above highlight that while patients with cervical cancer can gain benefit from the use of ICI therapy, responses are seen in the minority. Early reports of combination ICI appear to show improved response rates however further confirmatory data from randomised studies are awaited. Key to improving ICI efficacy is to identify potential biomarkers for response as well as considering ways to overcome immunotherapy resistance. Currently available biomarkers and selected strategies to overcome such resistance, including combining ICI with chemotherapy, radiotherapy and anti-angiogenics, are discussed below. Selected ongoing combination studies in early/locally advanced and recurrent/metastatic cervical cancer are highlighted in Tables 2 and 3, respectively. 
Table 2. Selected ongoing trials-Early/locally advanced cervical cancer.

\begin{tabular}{|c|c|c|c|}
\hline Trial Identifier & Study Phase & Study Population & Intervention \\
\hline NCT04221945 & III & $\begin{array}{l}\text { FIGO } 2014 \text { IB2-IIB (node positive), FIGO } 2014 \\
\text { II-IVA }\end{array}$ & CRT vs. CRT + concurrent and adjuvant pembrolizumab \\
\hline NCT03830866 & III & $\begin{array}{l}\text { FIGO (2009) Stages IB2 to IIB node positive or } \\
\text { FIGO (2009) IIIA-IVA any nodal status }\end{array}$ & $\begin{array}{l}\text { CRT vs. CRT + durvalumab then durvalumab } \\
\text { maintenance ( } 2 \text { years) }\end{array}$ \\
\hline NCT02635360 & II & - & $\begin{array}{l}\text { CRT + concurrent Pembrolizumab vs. CRT adjuvant } \\
\text { pembrolizumab }\end{array}$ \\
\hline NCT03527264 & II & FIGO 1B-IVA & $\begin{array}{c}\text { 1A: CRT + concurrent Nivolumab (whole pelvic RT) } \\
\text { 1B: CRT + concurrent Nivolumab (extended field RT) } \\
\text { 2: CRT + Nivolumab maintenance (total } 2 \text { years) } \\
\text { 3: CRT + concurrent Nivolumab then maintenance } \\
\text { Nivolumab (total } 2 \text { years) }\end{array}$ \\
\hline NCT03612791 & II & FIGO IB2-IVB (limited to PA nodes) & $\begin{array}{c}\text { CRT vs. CRT + concurrent atezolizumab (atezolizumab } \\
\text { total } 20 \text { cycles) }\end{array}$ \\
\hline NCT03833479 & II & $\begin{array}{l}\text { FIGO IB2/IIA2/IIB (positive pelvic LN) FIGO } \\
\text { IIIA/IIIB/IVA }\end{array}$ & CRT + consolidation TSR-042 (2 years) \\
\hline NCT04238988 & II & FIGO IB2-IIB & $\begin{array}{c}\text { Neoadjuvant carboplatin + paclitaxel + pembrolizumab } \\
\rightarrow \text { surgery } \rightarrow \text { Adjuvant carboplatin-paclitaxel- } \\
\text { pembrolizumab (high-risk patients) }\end{array}$ \\
\hline NCT01711515 & I & $\begin{array}{l}\text { FIGO (2014) IB2/IIA (+para-aortic LN), } \\
\text { IIB/IIIB/IVA }\end{array}$ & CRT + adjuvant Ipilimumab \\
\hline NCT04256213 & Pilot & FIGO IB3-IVA & Ipilimumab + Nivolumab + CRT \\
\hline
\end{tabular}

CRT, chemoradiotherapy; LN, lymph node; PA, para-aortic; RT, radiotherapy.

Table 3. Selected ongoing trials in advanced and metastatic cervical cancer.

\begin{tabular}{|c|c|c|c|c|}
\hline Trial Identifier & Study Phase & Treatment Status & Study Population & Intervention \\
\hline \multicolumn{5}{|c|}{ ICI + Chemotherapy } \\
\hline NCT03635567 & III & Naive & $\begin{array}{l}\text { Recurrence/metastatic cervical } \\
\text { cancer }\end{array}$ & $\begin{array}{c}\text { Cisplatin/Carboplatin + Paclitaxel + } \\
\text { Bevacizumab + Pembrolizumab/placebo }\end{array}$ \\
\hline NCT03556839 & III & Naive & $\begin{array}{l}\text { Stage IVB, persistent/recurrent } \\
\text { cervical cancer }\end{array}$ & $\begin{array}{l}\text { Cisplatin/Carboplatin + Paclitaxel + } \\
\text { Bevacizumab +/ - Atezolizumab }\end{array}$ \\
\hline NCT03340376 & II & Pre-treated & Recurrent/metastatic cervical cancer & $\begin{array}{l}\text { Atezolizumab vs. Doxorubicin vs. } \\
\text { Atezolizumab + Doxorubicin }\end{array}$ \\
\hline NCT03518606 & $\mathrm{I} / \mathrm{II}$ & Pre-treated & $\begin{array}{l}\text { Recurrent/metastatic Cervical, } \mathrm{H}+\mathrm{N} \text {, } \\
\text { Breast, Prostate cancer }\end{array}$ & $\begin{array}{c}\text { Durvalumab + Tremelimumab + } \\
\text { Vinorelbine }\end{array}$ \\
\hline NCT04188860 & II & Pre-treated & $\begin{array}{l}\text { Recurrent/persistent advanced } \\
\text { cervical cancer }\end{array}$ & Camrelizumab + Nab-paclitaxel \\
\hline \multicolumn{5}{|c|}{ ICI + Targeted Therapy } \\
\hline NCT03826589 & & Pre-treated & Recurrent/metastatic cervical cancer & Avelumab + Axitinib \\
\hline NCT04357873 & II & Naive/pre-treated & $\begin{array}{l}\text { Recurrent/Metastatic SCC (Vulvar, } \\
\text { Penile, Cervix, H + N, Anal) }\end{array}$ & Pembrolizumab + Vorinostat \\
\hline NCT04230954 & II & Naïve (PD-L1 CPS $\geq 1$ ) & $\begin{array}{l}\text { Recurrent/Metastatic Cervical } \\
\text { cancer }\end{array}$ & Pembrolizumab + Cabozantinib \\
\hline NCT04483544 & II & $\leq 2$ prior lines & & Pembrolizumab + Olaparib \\
\hline \multicolumn{5}{|c|}{ ICI + Radiotherapy } \\
\hline NCT03614949 & II & Naive/pre-treated & $\begin{array}{c}\text { Recurrent/metastatic Cervical cancer } \\
\text { or HPV positive SCC of } \\
\text { vagina/vulva. }\end{array}$ & Atezolizumab + SBRT (24Gy, 3 fractions) \\
\hline NCT03277482 & I & Pre-treated & $\begin{array}{l}\text { Recurrent/metastatic gynaecological } \\
\text { cancer }\end{array}$ & $\begin{array}{c}\text { Durvalumab, Tremelimumab + Radiation } \\
\text { therapy }\end{array}$ \\
\hline
\end{tabular}


Table 3. Cont.

\begin{tabular}{|c|c|c|c|c|}
\hline Trial Identifier & Study Phase & Treatment Status & Study Population & Intervention \\
\hline \multicolumn{5}{|c|}{ Vaccine Therapy + /- ICI } \\
\hline NCT03946358 & II & Pre-treated & $\begin{array}{l}\text { Pre-treated locally advanced/ } \\
\text { metastatic HPV associated cancers }\end{array}$ & Atezolizumab + UCPVax \\
\hline NCT04405349 & IIa & Pre-treated & HPV16 + 've cervical Ca & VB10.16 + Atezolizumab \\
\hline NCT03073525 & II & - & $\begin{array}{l}\text { Advanced gynaecological } \\
\text { malignancy }\end{array}$ & $\begin{array}{c}\text { Part 2:Vigil x2 } \rightarrow \text { Vigil + Atezolizumab } \\
\text { Part } 2 \text { comparator: Atezolizumab x2 } \rightarrow \\
\text { Atezolizumab + vigil }\end{array}$ \\
\hline NCT04432597 & $\mathrm{I} / \mathrm{II}$ & Naive/pre-treated & $\begin{array}{l}\text { Recurrent/metastatic HPV } \\
\text { associated cancer }\end{array}$ & PRGN-2009 +/ - M7824 \\
\hline NCT02866006 & $\mathrm{I} / \mathrm{II}$ & Pre-treated & $\begin{array}{l}\text { Recurrent/metastatic HPV 16/18 } \\
\text { positive Cervical cancer }\end{array}$ & BVAC-C \\
\hline NCT02128126 & $\mathrm{I} / \mathrm{II}$ & Naive & Recurrent/metastatic cervical cancer & $\begin{array}{l}\text { ISA101/ISA101b + Carboplatin + } \\
\text { paclitaxel +/ - Bevacizumab }\end{array}$ \\
\hline NCT04287868 & $\mathrm{I} / \mathrm{II}$ & Pre-treated & $\begin{array}{c}\text { Advanced HPV associated } \\
\text { malignancies }\end{array}$ & PDS0101 + M7824 + NHS-L12 \\
\hline
\end{tabular}

HPV, human papilloma virus; $\mathrm{H}+\mathrm{N}$, head and neck; SBRT, stereotactic body radiation therapy.

\subsection{Role of Biomarkers}

PDL1 is not expressed in normal cervical tissue [36] but is seen in malignant and premalignant lesions with reported rates of $95 \%$ and $80 \%$ in cervical intraepithelial neoplasia (CIN) and cervical SCC, respectively [36], while another study reported a low PDL1 expression rate of $24.9 \%$ in cervical SCC [37]. Reported expression levels vary partly due to the use of differing assays and cut-offs for positivity used. Rates of expression are lower in cervical adenocarcinoma compared to SCC with one study reporting PDL1 tumour cell positivity in $14 \%$ adenocarcinoma samples versus $54 \%$ SCC [38].

PDL1 is an FDA approved biomarker in cervical cancer with positive tumours eligible for single agent pembrolizumab after progression on first line chemotherapy based on results of KEYNOTE-158 discussed above [17]. PDL1 positivity was determined by a CPS $\geq 1$ using IHC 22C3 pharmDx assay, with CPS being the sum of PDL1-stained cells (tumour cells, lymphocytes, and macrophages) divided by the total number of viable tumour cells, multiplied by 100 [39]. Use of CPS positivity to identify those cancers who may benefit from PD1/PDL1 blockade would therefore seem appropriate, however other studies have reported responses in PDL1 negative tumours, including Checkmate-358 which used the IHC 28-8 pharmDx assay [18]. Whether these differences are a result of the different assays used, or that truly PDL1 is not a robust biomarker in cervical cancer is not clear. Heterogenicity in PDL1 expression may contribute to differing results regarding its role as a biomarker, with an analysis of paired primary and metastatic samples showing discordant tumour cell PDL1 expression in 31\% (22/71) of cases [38]. Alternative methods of PD1/PDL1 assessment beyond IHC have been assessed but are not in widespread use. Reports of PDL1 copy number analysis show the rate of amplification to be low, being seen in $2 \%$ of cervical SCC cases and $0.7 \%$ of a cohort of various solid tumour types making it a poor candidate $[40,41]$. Use of RNAish to detect PDL1 mRNA appears promising, with expression in $56 \%$ of tumour cells reported [41].

Tumour mutational burden (TMB) is calculated by assessing the number of nonsynonymous somatic mutations per mega-base $(\mathrm{mb})$ and is a surrogate for tumour neoantigen load and potential immunogenicity [42,43]. A study of 284 cervical SCC specimens showed a median TMB of 5.4 mutations $/ \mathrm{mb}$, with $6.7 \%$ cases exhibiting TMB $>20$ mutations $/ \mathrm{mb}$ [44]. Studies in lung cancer have suggested improved efficacy of ICI with higher TMB [45] and biomarker analysis of the basket study KEYNOTE 158 led to the approval of pembrolizumab in patients with high TMB ( $\geq 10$ mutations $/ \mathrm{mb}$ ) based on the companion diagnostic FoundationOne CDx assay. This analysis included 16 patients with cervical SCC 
with an ORR 31\% [46]. While this is promising and offers another avenue for patients to access ICI response rates remain modest.

Microsatellite instability or deficiency in mismatch repair proteins also represents a tumour agnostic indication for the use of pembrolizumab in refractory solid organ malignancies. In a study of 93 cases of cervical SCC, microsatellite instability-high was reported in $11.8 \%$, with a lower rate of $3.6 \%$ reported in a separate study $(n=168)[47,48]$.

A study of tumour draining lymph node and primary tumour samples identified $\mathrm{CD}^{+}{ }^{-} \mathrm{FoxP}^{+} \mathrm{CD}^{2} 5^{+}$effector $\mathrm{T}$ cells as a potential alternative biomarker for efficacy of PD-1/PDL1 blockade that merits investigation, with an association seen between the percentage this T cell subset and IFN $\gamma$ response after PD-1 inhibition in vitro using single cell suspensions [49].

As molecular biomarkers continue to be developed it is important to assess the role of clinical biomarkers in identifying those who may gain the most from ICI use. Retrospective studies including various tumour types have highlighted overweight and obese patients to have improved response rates versus non-overweight patients [50], possibly driven by immune dysregulation associated with obesity in pre-clinical models [51]. In NSCLC primary resistance to ICI therapy was seen to be associated with factors including never smokers, more involved sites, more prior treatments, and lower mean albumin [52]. Currently such clinical biomarkers to not play a role in treatment decisions and limited data is available for cervical cancer patients where further research is needed.

\subsection{Resistance Mechanisms and Treatment Strategies}

Resistance mechanisms to ICI therapy in cervical cancer are not well described. Work in lung cancer and melanoma has begun to highlight key tumour and host factors in such resistance to immunotherapy [53].

\subsubsection{Immunosuppressive Microenvironment}

Dysregulation of microenvironment can create an immunosuppressive, 'cold' and non-inflamed tumour. A study of 40 patients highlighted a change from Th1 to immunosuppressive Th2 state as pre-malignant lesions progressed from CIN-1 to CIN-3 [54]. Conversely, 'hot' inflamed tumours are associated with $\mathrm{T}$ cell infiltration, with tumour infiltrating lymphocytes (TILs) linked to improved survival $[55,56]$. Analysis of surgical specimens from 86 patients with FIGO I-II cervical SCC showed intra-epithelial M1 macrophages was associated with improved survival as well as high numbers of TILs [57].

An immunosuppressive microenvironment was seen in tumour draining lymph nodes involved by cervical carcinoma compared to lymph nodes free of tumour with higher number of CD4 and CD8 positive Tregs and increased expression of PDL1 and B7-H4, a coinhibitory molecule [58]. In vitro analysis highlighted an immunosuppressive cytokine profile in tumour involved lymph nodes consisting of higher levels of IL6, IL10, and TNF $\alpha$ released under stimulation, while IFN $\gamma$ release was high in cells from tumour free lymph nodes. The phase 1 DURVIT study assesses the safety of locally administered durvalumab in patients with cervical cancer planned for hysterectomy and lymph node dissection with key secondary endpoints assessing effect on the microenvironment of both the tumour and draining lymph nodes [59].

Mutations in PIK3CA have been associated with an immunosuppressive microenvironment and were reported in $40 \%$ patient patients in a prospective analysis of treatment naive cervical cancer [60]. When present in tandem with loss of function mutations in epigenetic pathway regulators (34\% of cases) PIK3CA mutations were associated with significantly shorter PFS. Mouse tumour models with a common PIK3CA mutation (H1047R) showed reduced infiltrate of CD8+ T cells and resistance to immunotherapy (anti PD-1) that could be reversed with PI3K inhibition [61]. Studies in melanoma also highlight role of PIK3-AKT pathway activation in immune resistance. Tumours with PTEN loss showed inferior reduction in tumour size versus those with retained expression after treatment with nivolumab or pembrolizumab, while a combination PI3K $\beta$ inhibition and anti-PD1 
therapy in mouse models of PTEN null melanoma achieved improved tumour control versus either agent alone [62]. An ongoing phase I trial is examining the role of combining the AKT inhibitor AZD5363 with durvalumab and olaparib in patients with treatment refractory solid organ malignancies with PIK3-AKT pathway mutations (NCT03772561).

\subsubsection{Role of VEGF Signalling}

Vascular endothelial growth factor (VEGF) is associated with immunosuppressive microenvironment and reduced lymphocyte influx in a number of tumours [63]. It is seen to prevent maturation of dendritic cells while leading to increased numbers of inhibitory Tregs and tumour associated macrophages [64]. Additionally, in vitro, VEGF-A appears to enhance expression of PD- 1 on CD-8 T cells thereby potentiating immunosuppressive signals [65]. Inhibition of VEGF signalling is associated with 'normalisation' of tumour vessels and CD8+ T cell response [63] and the combination of ICI and VEGF inhibition has become an attractive option to examine in clinical trials. Such combination strategies have shown a survival benefit in NSCLC [66], hepatocellular carcinoma [67] and renal cell carcinoma [68]. Anti-VEGF therapy is appealing in cervical cancer with upregulation of VEGF-A and VEGF receptor 1 seen in cases of recurrent disease [69] and addition of bevacizumab (anti-VEGF-A) to chemotherapy is currently first line standard of care for recurrent/metastatic cervical cancer in view of reported survival benefit over chemotherapy alone [7].

The CLAP study, a single arm phase II trial of anti-PD1 camrelizumab in combination with apatinib showed an impressive ORR of $55.6 \%$ in patients with pre-treated advanced cervical cancer [70]. In total. 33\% of patients were PDL1 negative or unknown with response seen in both PDL1 positive and negative cases. Ongoing phase III studies will inform regarding the role of such combinations in the first line setting. The first line study KEYNOTE 826 is assessing the addition of pembrolizumab or placebo to the combination of chemotherapy with or without bevacizumab (investigators choice), while the first line BEATcc study involves chemotherapy, bevacizumab with or without atezolizumab [71].

\subsubsection{Tumour Antigen Presentation}

Disruption of the antigen presentation pathway is seen across multiple tumour types as a mechanism of immune evasion and ICI resistance [72]. Mutations in $\beta_{2}$-microglobulin mutations affect MHC functioning and are associated with ICI resistance in melanoma and NSCLC $[73,74]$. Thiol reductase ERp57 has a role in MHC assembly, and its downregulation in cervical cancer and associated with worse OS [75,76].

Combinations including chemotherapy and/or radiotherapy can work to increase immunogenic cell death leading to the release of tumour associated neoantigens and cellular danger-associated molecular patterns, resulting in increased activity of APC and downstream $\mathrm{T}$ cell activation. Combining ICI with chemoradiotherapy is an attractive option with ongoing studies in the locally advanced setting including KEYNOTE-A18, a phase III trial evaluating the addition of pembrolizumab to standard of care concurrent chemoradiotherapy (NCT04221945). Table 2 highlights selected studies trialling similar combinations of ICI and concurrent chemoradiotherapy.

\subsubsection{Co-Inhibitory Signalling Pathways}

T cell immunoglobulin and mucin-domain-containing molecule 3 (TIM-3) negatively regulates immune response. TIM-3 is co-expressed with PD- 1 on CD-8+ T cells and is associated with $\mathrm{T}$ cell exhaustion with TIM3+ CD4 T cells producing less interferon- $\gamma$ and IL-2 than TIM3 negative cells [77,78]. In a study of 42 cervical SCC specimens TIM3 expression correlated with tumour grade and presence of metastasis [79]. Early phase trials are ongoing evaluating the role of TIM-3 inhibition alone and in combination with anti-PD1/PDL1 therapy in patients with advanced solid organ cancers (NCT03652077, NCT02608268). 
Upregulation of additional immune checkpoints including lymphocyte-activation gene 3 (LAG-3) has been seen in multiple cancers including cervical cancer and is thought to play a role in adaptive resistance to ICI $[80,81]$. DUET- 4 trial of the bispecific antibody targeting CTLA-4 and LAG-3 alone or in combination with pembrolizumab is an early phase study of patients with advanced malignancies including cervical cancer (NCT03849469).

T cell immunoglobulin and ITIM domain (TIGIT) binds to ligands CD155 and CD 112 exerting inhibitor signals on $\mathrm{T}$ cell response. Co-expression has been seen with other immune checkpoints in cervical cancer $[82,83]$. The ongoing SKYSCRAPER 04 examines the combination of atezolizumab alone and in combination with the anti-TGIT tiragolumab in patients with advanced cervical cancer after 1-2 prior lines of chemotherapy (NCT04300647).

\section{Immunotherapy beyond ICI}

Aside from ICI there are numerous immunotherapy strategies under investigation, including several in the setting of advanced cervical cancer discussed below.

\subsection{Cancer Vaccines}

The association of HPV and cervical SCC makes HPV related proteins attractive targets for vaccine based therapy. The vector vaccine ADXS11-001 is an attenuated live Listeria monocytogenes encoding the E7 oncoprotein. Initial results of the GOG/NRG0265 study of ADXS11-001 are promising with a 12 month OS rate of $38.5 \%$ in patients with pre-treated recurrent or metastatic cervical carcinoma (squamous and non-squamous) [84]. A combined 12 month OS rate of 34.9\% was seen in a phase II study of ADXS11-001 with and without cisplatin in patients with advanced cervical carcinoma [85].

Peptide vaccines are also under investigation. ISA101 consists of 12 synthetic long peptides from the E6/7 oncoproteins of HPV 16 and is combined with nivolumab in patients with advanced HPV16 positive tumours in a single arm phase II study (NCT02426892) including 1 patient with cervical cancer. ORR in the overall population was 33\% [86].

\subsection{Genome Editing Tools}

Research utilising clustered regularly interspaced palindromic repeats (CRISPR) associated protein 9 (Cas9) technology to enact genetic editing is a rapidly growing field [87].

Transcription Activator-Like Effector Nucleases (TALENs) also function as gene editing tools and TALEN targeting E7 oncoprotein is seen in vitro to downregulate E7 expression and lead to cell death [88]. A phase I study of CIN patients will evaluate TALEN-HPV E6/E7 and CRISPR/Cas9-HPV E6/E7 (NCT 03057912).

\subsection{Cell Based Therapy-Engineered T Cells}

Adoptive cell transfer is promising field with a phase II study involved patients receiving lymphodepletion with cyclophosphamide and fludarabine followed by infusion of TILs (LN-145), and up to 6 doses of IL-2 showed an impressive ORR of $44 \%$ in patients with advanced cervical cancer progressing on prior chemotherapy [89].

\section{Conclusions}

Significant challenges exist in our efforts to improve responses to ICI in cervical cancer. One of the key deficiencies remains the lack of more robust biomarkers beyond PD-L1 expression, high TMB or MSI-high. Even in tumours with these established biomarkers, response rates remain modest, but importantly long-lived in the minority of responders.

Encouraging improvements in efficacy have been observed with early reports of ICI doublet (anti-PD1/PDL1 and anti-CTLA4) and ICI plus anti-angiogenic therapy. Rationally designed clinical trials incorporating biomarker discovery with combination strategies, including the addition of PARP inhibitors, therapeutic vaccines and radiotherapy to ICI, will be crucial in unravelling the various mechanisms of ICI resistance that exist within 
cervical cancer. More importantly, the answers to these questions will be the key to expanding the role of ICIs in cervical cancer.

Author Contributions: Conceptualization, R.J.W. and D.S.P.T.; methodology, R.J.W. and D.S.P.T.; writing—original draft preparation, R.J.W. and D.S.P.T.; writing—review and editing, R.J.W. and D.S.P.T.; supervision, D.S.P.T. All authors have read and agreed to the published version of the manuscript.

Funding: D.S.P.T. is supported by the National Medical Research Council, Singapore (CSAINV16may008) and Pangestu Family Foundation Gynaecological Cancer Research Fund.

Institutional Review Board Statement: Not applicable.

Informed Consent Statement: Not applicable.

Conflicts of Interest: D.S.P.T. reports research support from AstraZeneca, Karyopharm Therapeutics, Bayer, Roche, National Medical Research Council Singapore, Pangestu Family Foundation Gynaecological Cancer Research Fund, and Cancer Science Institute Singapore; serves on the advisory board of AstraZeneca, MSD, Roche, Bayer, Experimental Drug Development Centre (EDDC) e A*Star Singapore, Genmab, Tessa Therapeutics, and Eisai; receives honoraria/travel support from AstraZeneca, Novartis, Roche, Merck Serono, MSD, Bayer, Genmab, Takeda, Eisai, and Clovis. R.J.W. reports no conflict of interest.

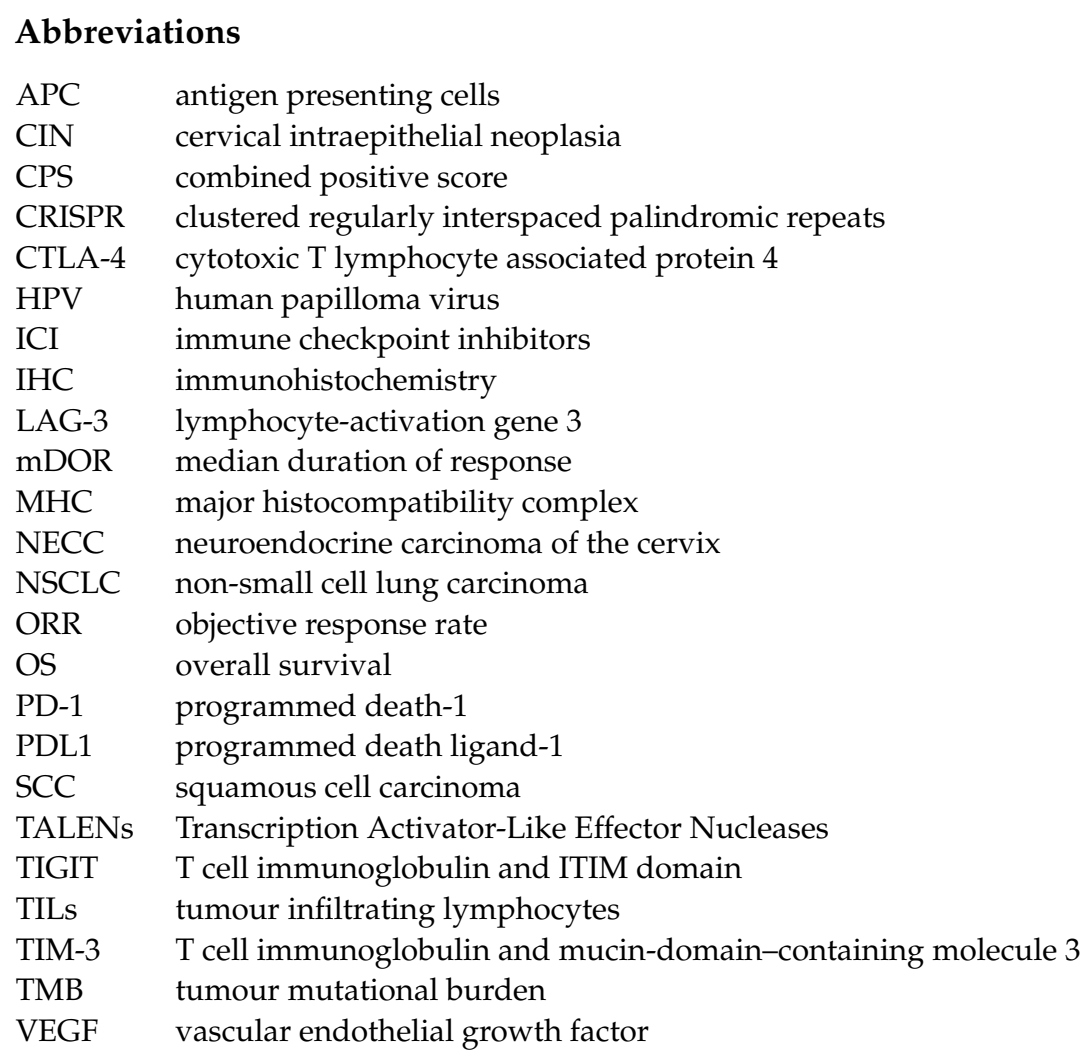

\section{References}

1. Bray, F.; Ferlay, J.; Soerjomataram, I.; Siegel, R.L.; Torre, L.A.; Jemal, A. Global cancer statistics 2018: GLOBOCAN estimates of incidence and mortality worldwide for 36 cancers in 185 countries. CA A Cancer J. Clin. 2018, 68, 394-424. [CrossRef]

2. Walboomers, J.M.; Jacobs, M.V.; Manos, M.M.; Bosch, F.X.; Kummer, J.A.; Shah, K.V.; Snijders, P.J.; Peto, J.; Meijer, C.J.; Muñoz, N. Human papillomavirus is a necessary cause of invasive cervical cancer worldwide. J. Pathol. 1999, 189, 12-19. [CrossRef]

3. Gupta, S.; Maheshwari, A.; Parab, P.; Mahantshetty, U.; Hawaldar, R.; Sastri, S.; Kerkar, R.; Engineer, R.; Tongaonkar, H.; Ghosh, J.; et al. Neoadjuvant Chemotherapy Followed by Radical Surgery Versus Concomitant Chemotherapy and Radiotherapy in Patients With Stage IB2, IIA, or IIB Squamous Cervical Cancer: A Randomized Controlled Trial. J. Clin. Oncol. 2018, 36, 1548-1555. [CrossRef] [PubMed] 
4. Morris, M.; Brader, K.R.; Levenback, C.; Burke, T.W.; Atkinson, E.N.; Scott, W.R.; Gershenson, D.M. Phase II study of vinorelbine in advanced and recurrent squamous cell carcinoma of the cervix. J. Clin. Oncol. 1998, 16, 1094-1098. [CrossRef]

5. Miller, D.S.; Blessing, J.A.; Bodurka, D.; Bonebrake, A.J.; Schorge, J.O. Evaluation of pemetrexed (Alimta, LY231514) as second line chemotherapy in persistent or recurrent carcinoma of the cervix: A phase II study of the Gynecologic Oncology Group. Gynecol. Oncol. 2008, 110, 65-70. [CrossRef]

6. Lhommé, C.; Fumoleau, P.; Fargeot, P.; Krakowski, Y.; Dieras, V.; Chauvergne, J.; Vennin, P.; Rebattu, P.; Roche, H.; Misset, J.-L.; et al. Results of a European Organization for Research and Treatment of Cancer/Early Clinical Studies Group Phase II Trial of First-Line Irinotecan in Patients With Advanced or Recurrent Squamous Cell Carcinoma of the Cervix. J. Clin. Oncol. 1999, 17, 3136-3142. [CrossRef] [PubMed]

7. Tewari, K.S.; Sill, M.W.; Penson, R.T.; Huang, H.; Ramondetta, L.M.; Landrum, L.M.; Oaknin, A.; Reid, T.J.; Leitao, M.M.; E Michael, H.; et al. Bevacizumab for advanced cervical cancer: Final overall survival and adverse event analysis of a randomised, controlled, open-label, phase 3 trial (Gynecologic Oncology Group 240). Lancet 2017, 390, 1654-1663. [CrossRef]

8. Chen, D.S.; Mellman, I. Oncology meets immunology: The cancer-immunity cycle. Immunity 2013, 39, 1-10. [CrossRef] [PubMed]

9. Pardoll, D.M. The blockade of immune checkpoints in cancer immunotherapy. Nat. Rev. Cancer 2012, 12, 252-264. [CrossRef] [PubMed]

10. André, T.; Shiu, K.-K.; Kim, T.W.; Jensen, B.V.; Jensen, L.H.; Punt, C.; Smith, D.; Garcia-Carbonero, R.; Benavides, M.; Gibbs, P.; et al. Pembrolizumab in Microsatellite-Instability-High Advanced Colorectal Cancer. N. Engl. J. Med. 2020, 383, $2207-2218$. [CrossRef] [PubMed]

11. Emens, L.A.; Ascierto, P.A.; Darcy, P.; Demaria, S.; Eggermont, A.M.; Redmond, W.L.; Seliger, B.; Marincola, F.M. Cancer immunotherapy: Opportunities and challenges in the rapidly evolving clinical landscape. Eur. J. Cancer 2017, 81, 116-129. [CrossRef] [PubMed]

12. Low, J.L.; Walsh, R.J.; Ang, Y.; Chan, G.; Soo, R.A. The evolving immuno-oncology landscape in advanced lung cancer: First-line treatment of non-small cell lung cancer. Ther. Adv. Med. Oncol. 2019, 11, 1758835919870360. [CrossRef] [PubMed]

13. Brown, L.C.; Desai, K.; Zhang, T.; Ornstein, M.C. The Immunotherapy Landscape in Renal Cell Carcinoma. BioDrugs 2020, 34, 733-748. [CrossRef] [PubMed]

14. Allouch, S.; Malki, A.; Allouch, A.; Gupta, I.; Vranic, S.; Al Moustafa, A.-E. High-Risk HPV Oncoproteins and PD-1/PD-L1 Interplay in Human Cervical Cancer: Recent Evidence and Future Directions. Front. Oncol. 2020, 10, 914. [CrossRef] [PubMed]

15. Tewari, K.S.; Monk, B.J.; Vergote, I.; Miller, A.; de Melo, A.C.; Kim, H.S.; Kim, Y.M.; Lisyanskaya, A.; Samouëlian, V.; Lorusso, D.; et al. VP4-2021: EMPOWER-Cervical 1/GOG-3016/ENGOT-cx9: Interim analysis of phase III trial of cemiplimab vs. investigator's choice (IC) chemotherapy (chemo) in recurrent/metastatic (R/M) cervical carcinoma. Ann. Oncol. 2021, 32, 940-941. [CrossRef]

16. Frenel, J.S.; Le Tourneau, C.; O’Neil, B.; Ott, P.A.; Piha-Paul, S.A.; Gomez-Roca, C.; van Brummelen, E.M.J.; Rugo, H.S.; Thomas, S.; Saraf, S.; et al. Safety and Efficacy of Pembrolizumab in Advanced, Programmed Death Ligand 1-Positive Cervical Cancer: Results From the Phase Ib KEYNOTE-028 Trial. J. Clin. Oncol. 2017, 35, 4035-4041. [CrossRef]

17. Chung, H.; Ros, W.; Delord, J.-P.; Perets, R.; Italiano, A.; Shapira-Frommer, R.; Manzuk, L.; Piha-Paul, S.; Xu, L.; Zeigenfuss, S.; et al. Efficacy and Safety of Pembrolizumab in Previously Treated Advanced Cervical Cancer: Results From the Phase II KEYNOTE-158 Study. J. Clin. Oncol. 2019, 37, 1470-1478. [CrossRef]

18. Naumann, R.W.; Hollebecque, A.; Meyer, T.; Devlin, M.-J.; Oaknin, A.; Kerger, J.; López-Picazo, J.M.; Machiels, J.-P.; Delord, J.-P.; Evans, T.R.J.; et al. Safety and Efficacy of Nivolumab Monotherapy in Recurrent or Metastatic Cervical, Vaginal, or Vulvar Carcinoma: Results From the Phase I/II CheckMate 358 Trial. J. Clin. Oncol. 2019, 37, 2825-2834. [CrossRef]

19. Santin, A.D.; Deng, W.; Frumovitz, M.; Buza, N.; Bellone, S.; Huh, W.; Khleif, S.; Lankes, H.A.; Ratner, E.S.; O'Cearbhaill, R.E.; et al. Phase II evaluation of nivolumab in the treatment of persistent or recurrent cervical cancer (NCT02257528/NRG-GY002). Gynecol. Oncol. 2020, 157, 161-166. [CrossRef]

20. Lheureux, S.; Butler, M.; Clarke, B.; Cristea, M.C.; Martin, L.P.; Tonkin, K.; Fleming, G.F.; Tinker, A.V.; Hirte, H.W.; Tsoref, D.; et al. Association of Ipilimumab With Safety and Antitumor Activity in Women With Metastatic or Recurrent Human Papillomavirus-Related Cervical Carcinoma. JAMA Oncol. 2018, 4, e173776. [CrossRef]

21. US Food and Drug Administration. 2018. Available online: https://www.fda.gov/drugs/resources-information-approveddrugs/fda-approves-pembrolizumab-advanced-cervical-cancer-disease-progression-during-or-after-chemotherapy (accessed on 30 June 2021).

22. Drescher, C.; Moore, K.; Liu, J.; O’Malley, D.; Wang, E.; Wang, J.-Z.; Subbiah, V.; Wilky, B.; Yuan, G.; Dupont, C.; et al. Phase I/II, open-label, multiple ascending dose trial of AGEN2034, an anti-PD-1 monoclonal antibody, in advanced solid malignancies: Results of dose escalation in advanced cancer and expansion cohorts in subjects with relapsed/refractory cervical cancer. Ann. Oncol. 2018, 29, viii412-viii413. [CrossRef]

23. Kudo, M. Scientific Rationale for Combination Immunotherapy of Hepatocellular Carcinoma with Anti-PD-1/PD-L1 and Anti-CTLA-4 Antibodies. Liver Cancer 2019, 8, 413-426. [CrossRef]

24. Baas, P.; Scherpereel, A.; Nowak, A.; Fujimoto, N.; Peters, S.; Tsao, A.; Mansfield, A.; Popat, S.; Jahan, T.; Antonia, S.; et al. ID:2908 First-Line Nivolumab + Ipilimumab vs Chemotherapy in Unresectable Malignant Pleural Mesothelioma: CheckMate 743. J. Thorac. Oncol. 2020, 15, e42. [CrossRef] 
25. Motzer, R.J.; I Rini, B.; McDermott, D.F.; Frontera, O.A.; Hammers, H.J.; A Carducci, M.; Salman, P.; Escudier, B.; Beuselinck, B.; Amin, A.; et al. Nivolumab plus ipilimumab versus sunitinib in first-line treatment for advanced renal cell carcinoma: Extended follow-up of efficacy and safety results from a randomised, controlled, phase 3 trial. Lancet Oncol. 2019, 20, 1370-1385. [CrossRef]

26. Naumann, R.W.; Oaknin, A.; Meyer, T.; Lopez-Picazo, J.M.; Lao, C.; Bang, Y.J.; Boni, V.; Sharfman, W.H.; Park, J.C.; Devriese, L.A.; et al. LBA62Efficacy and safety of nivolumab (Nivo) + ipilimumab (Ipi) in patients (pts) with recurrent/metastatic (R/M) cervical cancer: Results from CheckMate 358. Ann. Oncol. 2019, 30, v898-v899. [CrossRef]

27. O’Malley, D.; Oaknin, A.; Monk, B.; Leary, A.; Selle, F.; Alexandre, J.; Randall, L.; Rojas, C.; Neffa, M.; Kryzhanivska, A.; et al. LBA34 Single-agent anti-PD-1 balstilimab or in combination with anti-CTLA-4 zalifrelimab for recurrent/metastatic (R/M) cervical cancer (CC): Preliminary results of two independent phase II trials. Ann. Oncol. 2020, 31, S1164-S1165. [CrossRef]

28. Callahan, M.K.; Odunsi, K.; Sznol, M.; Nemunaitis, J.J.; Ott, P.A.; Dillon, P.M.; Park, A.J.; Schwarzenberger, P.; Ricciardi, T.; Macri, M.J.; et al. Phase 1 study to evaluate the safety and tolerability of MEDI4736 (durvalumab, DUR) + tremelimumab (TRE) in patients with advanced solid tumors. J. Clin. Oncol. 2017, 35, 3069. [CrossRef]

29. Coward, J.; Lemech, C.; Meniawy, T.; Dupont, C.; Gonzalez, A.; Lim, M.; Savitsky, D.; Carini, M.; Hu, S.; Shebanova, O.; et al. Phase I/II study of CTLA-4 inhibitor AGEN1884 + PD-1 Inhibitor AGEN2034 in patients with advanced/refractory solid tumors, with expansion into 2L cervical cancer and solid tumors. Ann. Oncol. 2018, 29, viii417. [CrossRef]

30. Tempfer, C.B.; Tischoff, I.; Dogan, A.; Hilal, Z.; Schultheis, B.; Kern, P.; Rezniczek, G.A. Neuroendocrine carcinoma of the cervix: A systematic review of the literature. BMC Cancer 2018, 18, 530. [CrossRef]

31. Paraghamian, S.E.; Longoria, T.C.; Eskander, R.N. Metastatic small cell neuroendocrine carcinoma of the cervix treated with the PD-1 inhibitor, nivolumab: A case report. Gynecol. Oncol. Res. Pract. 2017, 4, 3. [CrossRef]

32. Castle, P.E.; Pierz, A.; Stoler, M.H. A systematic review and meta-analysis on the attribution of human papillomavirus (HPV) in neuroendocrine cancers of the cervix. Gynecol. Oncol. 2018, 148, 422-429. [CrossRef]

33. Paz-Ares, L.; Dvorkin, M.; Chen, Y.; Reinmuth, N.; Hotta, K.; Trukhin, D.; Statsenko, G.; Hochmair, M.J.; Özgüroğlu, M.; Ji, J.H.; et al. Durvalumab plus platinum-etoposide versus platinum-etoposide in first-line treatment of extensive-stage small-cell lung cancer (CASPIAN): A randomised, controlled, open-label, phase 3 trial. Lancet 2019, 394, 1929-1939. [CrossRef]

34. Horn, L.; Mansfield, A.S.; Szczęsna, A.; Havel, L.; Krzakowski, M.; Hochmair, M.J.; Huemer, F.; Losonczy, G.; Johnson, M.L.; Nishio, M.; et al. First-Line Atezolizumab plus Chemotherapy in Extensive-Stage Small-Cell Lung Cancer. N. Engl. J. Med. 2018, 379, 2220-2229. [CrossRef]

35. Ready, N.E.; Ott, P.A.; Hellmann, M.D.; Zugazagoitia, J.; Hann, C.L.; de Braud, F.; Antonia, S.J.; Ascierto, P.A.; Moreno, V.; Atmaca, A.; et al. Nivolumab Monotherapy and Nivolumab Plus Ipilimumab in Recurrent Small Cell Lung Cancer: Results From the CheckMate 032 Randomized Cohort. J. Thorac. Oncol. 2020, 15, 426-435. [CrossRef] [PubMed]

36. Mezache, L.; Paniccia, B.; Nyinawabera, A.; Nuovo, G.J. Enhanced expression of PD L1 in cervical intraepithelial neoplasia and cervical cancers. Mod. Pathol. 2015, 28, 1594-1602. [CrossRef] [PubMed]

37. Koncar, R.F.; Feldman, R.; Bahassi, E.M.; Hashemi Sadraei, N. Comparative molecular profiling of HPV-induced squamous cell carcinomas. Cancer Med. 2017, 6, 1673-1685. [CrossRef] [PubMed]

38. Heeren, A.M.; Punt, S.; Bleeker, M.C.; Gaarenstroom, K.N.; Van Der Velden, J.; Kenter, G.G.; de Gruijl, T.D.; Jordanova, E.S. Prognostic effect of different PD-L1 expression patterns in squamous cell carcinoma and adenocarcinoma of the cervix. Mod. Pathol. 2016, 29, 753-763. [CrossRef] [PubMed]

39. Frederick, J.; Guerrero, L.; Evans, T.; Barreto, J.; Kulangara, K. Abstract 749: Pathology training for combined positive score algorithm for the assessment of PD-L1 in human cancer tissues. Cancer Res. 2020, 80, 749.

40. Goodman, A.M.; Piccioni, D.; Kato, S.; Boichard, A.; Wang, H.-Y.; Frampton, G.; Lippman, S.M.; Connelly, C.; Fabrizio, D.; Miller, V.; et al. Prevalence of PDL1 Amplification and Preliminary Response to Immune Checkpoint Blockade in Solid Tumors. JAMA Oncol. 2018, 4, 1237-1244. [CrossRef]

41. Rotman, J.; Den Otter, L.A.; Bleeker, M.C.; Samuels, S.S.; Heeren, A.M.; Roemer, M.G.; Kenter, G.G.; Zijlmans, H.J.M.A.A.; van Trommel, N.E.; de Gruijl, T.D.; et al. PD-L1 and PD-L2 Expression in Cervical Cancer: Regulation and Biomarker Potential. Front. Immunol. 2020, 11, 596825. [CrossRef]

42. Wood, M.A.; Weeder, B.; David, J.; Nellore, A.; Thompson, R.F. Burden of tumor mutations, neoepitopes, and other variants are weak predictors of cancer immunotherapy response and overall survival. Genome Med. 2020, 12, 33. [CrossRef] [PubMed]

43. Xu, Z.; Dai, J.; Wang, D.; Lu, H.; Dai, H.; Ye, H.; Gu, J.; Chen, S.; Huang, B. Assessment of tumor mutation burden calculation from gene panel sequencing data. Onco Targets Ther. 2019, 12, 3401-3409. [CrossRef] [PubMed]

44. Chalmers, Z.R.; Connelly, C.F.; Fabrizio, D.; Gay, L.; Ali, S.M.; Ennis, R.; Schrock, A.; Campbell, B.; Shlien, A.; Chmielecki, J.; et al. Analysis of 100,000 human cancer genomes reveals the landscape of tumor mutational burden. Genome Med. $2017,9,34$. [CrossRef]

45. Gandara, D.R.; Kowanetz, M.; Mok, T.S.K.; Rittmeyer, A.; Fehrenbacher, L.; Fabrizio, D.; Otto, G.; Malboeuf, C.; Lieber, D.; Paul, S.M.; et al. Blood-based biomarkers for cancer immunotherapy: Tumor mutational burden in blood (bTMB) is associated with improved atezolizumab (atezo) efficacy in 2L+ NSCLC (POPLAR and OAK). Ann. Oncol. 2017, 28, v460. [CrossRef]

46. Marabelle, A.; Fakih, M.; Lopez, J.; Shah, M.; Shapira-Frommer, R.; Nakagawa, K.; Chung, H.C.; Kindler, H.L.; A Lopez-Martin, J.; Miller, W.H.; et al. Association of tumour mutational burden with outcomes in patients with advanced solid tumours treated with pembrolizumab: Prospective biomarker analysis of the multicohort, open-label, phase 2 KEYNOTE-158 study. Lancet Oncol. 2020, 21, 1353-1365. [CrossRef] 
47. Wong, Y.-F.; Cheung, T.-H.; Poon, K.-Y.; Wang, V.W.; Li, J.C.; Lo, K.W.-K.; Yim, S.-F.; Yu, M.-Y.; Lahr, G.; Chung, T.K.-H. The role of microsatellite instability in cervical intraepithelial neoplasia and squamous cell carcinoma of the cervix. Gynecol. Oncol. 2003, 89, 434-439. [CrossRef]

48. VanderWalde, A.; Spetzler, D.; Xiao, N.; Gatalica, Z.; Marshall, J. Microsatellite instability status determined by next-generation sequencing and compared with PD-L1 and tumor mutational burden in 11,348 patients. Cancer Med. 2018, 7, 746-756. [CrossRef]

49. Heeren, A.M.; Rotman, J.; Stam, A.G.M.; Pocorni, N.; Gassama, A.A.; Samuels, S.; Bleeker, M.C.G.; Mom, C.H.; Zijlmans, H.J.M.A.A.; Kenter, G.G.; et al. Efficacy of PD-1 blockade in cervical cancer is related to a CD8+ FoxP3+ CD25+ T-cell subset with operational effector functions despite high immune checkpoint levels. J. ImmunoTher. Cancer 2019, 7, 43. [CrossRef]

50. Cortellini, A.; Bersanelli, M.; Buti, S.; Cannita, K.; Santini, D.; Perrone, F.; Giusti, R.; Tiseo, M.; Michiara, M.; Di Marino, P.; et al. A multicenter study of body mass index in cancer patients treated with anti-PD-1/PD-L1 immune checkpoint inhibitors: When overweight becomes favorable. J. ImmunoTher. Cancer 2019, 7, 57. [CrossRef]

51. Mullen, M.; Gonzalez-Perez, R.R. Leptin-Induced JAK/STAT Signaling and Cancer Growth. Vaccines 2016, 4, 26. [CrossRef]

52. Shah, S.; Wood, K.; Labadie, B.; Won, B.; Brisson, R.; Karrison, T.; Hensing, T.; Kozloff, M.; Bao, R.; Patel, J.D.; et al. Clinical and molecular features of innate and acquired resistance to anti-PD-1/PD-L1 therapy in lung cancer. Oncotarget 2017, 9, 4375-4384. [CrossRef] [PubMed]

53. Walsh, R.J.; Soo, R.A. Resistance to immune checkpoint inhibitors in non-small cell lung cancer: Biomarkers and therapeutic strategies. Ther. Adv. Med. Oncol. 2020, 12, 1758835920937902. [CrossRef] [PubMed]

54. Yang, W.; Song, Y.; Lu, Y.-L.; Sun, J.-Z.; Wang, H.-W. Increased expression of programmed death (PD)-1 and its ligand PD-L1 correlates with impaired cell-mediated immunity in high-risk human papillomavirus-related cervical intraepithelial neoplasia. Immunology 2013, 139, 513-522. [CrossRef] [PubMed]

55. Chao, H.T.; Wang, P.H.; Tseng, J.Y.; Lai, C.R.; Chiang, S.C.; Yuan, C.C. Lymphocyte-infiltrated FIGO Stage IIB squamous cell carcinoma of the cervix is a prominent factor for disease-free survival. Eur. J. Gynaecol. Oncol. 1999, 20, 136-140.

56. Duan, Q.; Zhang, H.; Zheng, J.; Zhang, L. Turning Cold into Hot: Firing up the Tumor Microenvironment. Trends Cancer 2020, 6, 605-618. [CrossRef]

57. De Vos van Steenwijk, P.J.; Ramwadhdoebe, T.H.; Goedemans, R.; Doorduijn, E.M.; Van Ham, J.J.; Gorter, A.; van Hall, T.; Kuijjer M.L.; van Poelgeest, M.I.E.; van der Burg, S.H.; et al. Tumor-infiltrating CD14-positive myeloid cells and CD8-positive T-cells prolong survival in patients with cervical carcinoma. Int. J. Cancer 2013, 133, 2884-2894. [CrossRef]

58. Heeren, A.M.; Koster, B.D.; Samuels, S.; Ferns, D.M.; Chondronasiou, D.; Kenter, G.G.; Jordanova, E.S.; de Gruijl, T.D. High and interrelated rates of PD-L1+ CD14+ antigen-presenting cells and regulatory T cells mark the microenvironment of metastatic lymph nodes from patients with cervical cancer. Cancer Immunol. Res. 2015, 3, 48. [CrossRef]

59. Rotman, J.; Mom, C.H.; Jordanova, E.S.; De Gruijl, T.D.; Kenter, G.G. 'DURVIT': A phase-I trial of single low-dose durvalumab (Medi4736) IntraTumourally injected in cervical cancer: Safety, toxicity and effect on the primary tumour- and lymph node microenvironment. BMC Cancer 2018, 18, 888. [CrossRef]

60. Scholl, S.; Popovic, M.; de la Rochefordiere, A.; Girard, E.; Dureau, S.; Mandic, A.; Koprivsek, K.; Samet, N.; Craina, M.; Margan, M.; et al. Clinical and genetic landscape of treatment naive cervical cancer: Alterations in PIK3CA and in epigenetic modulators associated with sub-optimal outcome. EBioMedicine 2019, 43, 253-260. [CrossRef]

61. Collins, N.B.; Al Abosy, R.; Miller, B.; Bi, K.; Manguso, R.; Yates, K.; Haining, W.N. PI3K activated tumors evade tumor immunity by promoting an inhibitory myeloid microenvironment. J. Immunol. 2019, 202, 58.17.

62. Peng, W.; Chen, J.Q.; Liu, C.; Malu, S.; Creasy, C.; Tetzlaff, M.T.; Xu, C.; McKenzie, J.A.; Zhang, C.; Liang, X.; et al. Loss of PTEN Promotes Resistance to T Cell-Mediated Immunotherapy. Cancer Discov. 2016, 6, 202-216. [CrossRef] [PubMed]

63. De Aguiar, R.B.; de Moraes, J.Z. Exploring the Immunological Mechanisms Underlying the Anti-vascular Endothelial Growth Factor Activity in Tumors. Front. Immunol. 2019, 10, 1023. [CrossRef] [PubMed]

64. Tamura, R.; Tanaka, T.; Akasaki, Y.; Murayama, Y.; Yoshida, K.; Sasaki, H. The role of vascular endothelial growth factor in the hypoxic and immunosuppressive tumor microenvironment: Perspectives for therapeutic implications. Med. Oncol. 2019, 37, 2. [CrossRef] [PubMed]

65. Voron, T.; Colussi, O.; Marcheteau, E.; Pernot, S.; Nizard, M.; Pointet, A.-L.; Latreche, S.; Bergaya, S.; Benhamouda, N.; Tanchot, C.; et al. VEGF-A modulates expression of inhibitory checkpoints on CD8+ T cells in tumors. J. Exp. Med. 2015, 212, 139-148. [CrossRef] [PubMed]

66. Socinski, M.A.; Jotte, R.M.; Cappuzzo, F.; Orlandi, F.; Stroyakovskiy, D.; Nogami, N.; Rodríguez-Abreu, D.; Moro-Sibilot, D.; Thomas, C.A.; Barlesi, F.; et al. Atezolizumab for First-Line Treatment of Metastatic Nonsquamous NSCLC. N. Engl. J. Med. 2018, 378, 2288-2301. [CrossRef]

67. Finn, R.S.; Qin, S.; Ikeda, M.; Galle, P.R.; Ducreux, M.; Kim, T.-Y.; Kudo, M.; Breder, V.; Merle, P.; Kaseb, A.O. Atezolizumab plus Bevacizumab in Unresectable Hepatocellular Carcinoma. N. Engl. J. Med. 2020, 382, 1894-1905. [CrossRef]

68. Rini, B.I.; Plimack, E.R.; Stus, V.; Gafanov, R.; Hawkins, R.; Nosov, D.; Pouliot, F.; Alekseev, B.; Soulières, D.; Melichar, B.; et al. Pembrolizumab plus Axitinib versus Sunitinib for Advanced Renal-Cell Carcinoma. N. Engl. J. Med. 2019, 380, 1116-1127. [CrossRef]

69. Yoshida, K.; Suzuki, S.; Sakata, J.; Utsumi, F.; Niimi, K.; Yoshikawa, N.; Nishino, K.; Shibata, K.; Kikkawa, F.; Kajiyama, H. The upregulated expression of vascular endothelial growth factor in surgically treated patients with recurrent/radioresistant cervical cancer of the uterus. Oncol. Lett. 2018, 16, 515-521. [CrossRef] 
70. Lan, C.; Shen, J.; Wang, Y.; Li, J.; Liu, Z.; He, M.; Cao, X.; Ling, J.; Huang, J.; Zheng, M.; et al. Camrelizumab Plus Apatinib in Patients With Advanced Cervical Cancer (CLAP): A Multicenter, Open-Label, Single-Arm, Phase II Trial. J. Clin. Oncol. 2020, 38, 4095-4106. [CrossRef]

71. Grau, J.F.; Farinas-Madrid, L.; Oaknin, A. A randomized phase III trial of platinum chemotherapy plus paclitaxel with bevacizumab and atezolizumab versus platinum chemotherapy plus paclitaxel and bevacizumab in metastatic (stage IVB), persistent, or recurrent carcinoma of the cervix: The BEATcc study (ENGOT-Cx10/GEICO 68-C/JGOG1084/GOG-3030). Int. J. Gynecol. Cancer 2020, 30, 139-143.

72. Syn, N.L.; Teng, M.W.L.; Mok, T.S.K.; Soo, R.A. De-novo and acquired resistance to immune checkpoint targeting. Lancet Oncol. 2017, 18, e731-e741. [CrossRef]

73. Sade-Feldman, M.; Jiao, Y.J.; Chen, J.H.; Rooney, M.S.; Barzily-Rokni, M.; Eliane, J.-P.; Bjorgaard, S.L.; Hammond, M.R.; Vitzthum, H.; Blackmon, S.M.; et al. Resistance to checkpoint blockade therapy through inactivation of antigen presentation. Nat. Commun. 2017, 8, 1136. [CrossRef]

74. Gettinger, S.; Choi, J.; Hastings, K.; Truini, A.; Datar, I.; Sowell, R.; Wurtz, A.; Dong, W.; Cai, G.; Melnick, M.A.; et al. Impaired HLA Class I Antigen Processing and Presentation as a Mechanism of Acquired Resistance to Immune Checkpoint Inhibitors in Lung Cancer. Cancer Discov. 2017, 7, 1420-1435. [CrossRef]

75. Morrice, N.A.; Powis, S.J. A role for the thiol-dependent reductase ERp57 in the assembly of MHC class I molecules. Curr. Biol. 1998, 8, 713-716. [CrossRef]

76. Chung, H.; Cho, H.; Perry, C.; Song, J.; Ylaya, K.; Lee, H.; Kim, J.-H. Downregulation of ERp57 expression is associated with poor prognosis in early-stage cervical cancer. Biomarkers 2013, 18, 573-579. [CrossRef] [PubMed]

77. Yan, J.; Zhang, Y.; Zhang, J.-P.; Liang, J.; Li, L.; Zheng, L. Tim-3 expression defines regulatory T cells in human tumors. PLoS ONE 2013, 8, e58006. [CrossRef]

78. Fourcade, J.; Sun, Z.; Benallaoua, M.; Guillaume, P.; Luescher, I.F.; Sander, C.; Kirkwood, J.M.; Kuchroo, V.; Zarour, H.M. Upregulation of Tim-3 and PD-1 expression is associated with tumor antigen-specific CD8+ T cell dysfunction in melanoma patients. J. Exp. Med. 2010, 207, 2175-2186. [CrossRef] [PubMed]

79. Cao, Y.; Zhou, X.; Huang, X.; Li, Q.; Gao, L.; Jiang, L.; Huang, M.; Zhou, J. Tim-3 expression in cervical cancer promotes tumor metastasis. PLoS ONE 2013, 8, e53834. [CrossRef]

80. Chen, F.; Sherwood, T.; De Costa, A.; Yee-Toy, N.; Lung, P.; Easton, A.; Sumrow, B.; Bonvini, E.; Moore, P.A. Immunohistochemistry analyses of LAG-3 expression across different tumor types and co-expression with PD-1. J. Clin. Oncol. 2020, 38, e15086. [CrossRef]

81. Huang, R.-Y.; Francois, A.; McGray, A.R.; Miliotto, A.; Odunsi, K. Compensatory upregulation of PD-1, LAG-3, and CTLA-4 limits the efficacy of single-agent checkpoint blockade in metastatic ovarian cancer. Oncoimmunology 2017, 6, e1249561. [CrossRef]

82. Qin, S.; Xu, L.; Yi, M.; Yu, S.; Wu, K.; Luo, S. Novel immune checkpoint targets: Moving beyond PD-1 and CTLA-4. Mol. Cancer 2019, 18, 155. [CrossRef] [PubMed]

83. Li, X.; Wang, R.; Fan, P.; Yao, X.; Qin, L.; Peng, Y.; Ma, M.; Asley, N.; Chang, X.; Feng, Y.; et al. A Comprehensive Analysis of Key Immune Checkpoint Receptors on Tumor-Infiltrating T Cells From Multiple Types of Cancer. Front. Oncol. 2019, 9, 1066. [CrossRef]

84. Huh, W.K.; Dizon, D.S.; Powell, M.A.; Leath, C.A.; Landrum, L.M.; Tanner, E.; Higgins, R.; Ueda, S.M.; McHale, M.T.; Monk, B.J.; et al. ADXS11-001 immunotherapy in squamous or non-squamous persistent/recurrent metastatic cervical cancer: Results from stage I of the phase II GOG/NRG0265 study. J. Clin. Oncol. 2016, 34, 5516. [CrossRef]

85. Basu, P.; Mehta, A.; Jain, M.; Gupta, S.; Nagarkar, R.V.; John, S.; Petit, R. A Randomized Phase 2 Study of ADXS11-001 Listeria monocytogenes-Listeriolysin O Immunotherapy With or Without Cisplatin in Treatment of Advanced Cervical Cancer. Int. J. Gynecol. Cancer 2018, 28, 764-772. [CrossRef]

86. Massarelli, E.; William, W.; Johnson, F.; Kies, M.; Ferrarotto, R.; Guo, M.; Feng, L.; Lee, J.J.; Tran, H.; Kim, Y.U.; et al. Combining Immune Checkpoint Blockade and Tumor-Specific Vaccine for Patients With Incurable Human Papillomavirus 16-Related Cancer: A Phase 2 Clinical Trial. JAMA Oncol. 2019, 5, 67-73. [CrossRef] [PubMed]

87. Akram, F.; Ul Haq, I.; Ahmed, Z.; Khan, H.; Ali, M.S. CRISPR-Cas9, A Promising Therapeutic Tool for Cancer Therapy: A Review. Protein Pept. Lett. 2020, 27, 931-944. [CrossRef] [PubMed]

88. Shankar, S.; Prasad, D.; Sanawar, R.; Das, A.V.; Pillai, M.R. TALEN based HPV-E7 editing triggers necrotic cell death in cervical cancer cells. Sci. Rep. 2017, 7, 5500. [CrossRef]

89. Jazaeri, A.A.; Zsiros, E.; Amaria, R.N.; Artz, A.S.; Edwards, R.P.; Wenham, R.M.; Slomovitz, B.M.; Walther, A.; Thomas, S.S.; Chesney, J.A.; et al. Safety and efficacy of adoptive cell transfer using autologous tumor infiltrating lymphocytes (LN-145) for treatment of recurrent, metastatic, or persistent cervical carcinoma. J. Clin. Oncol. 2019, 37, 2538. [CrossRef] 